\title{
El maestro: historia de un oficio
}

Alejandro Alvarez Gallego **

\author{
"Las Escuelas Normales de Institutores son Escuelas de \\ Oficio. El Oficio del maestro es enseñar". \\ Curso Superior de Pedagogía, 1894.
}

\section{Presentación}

Aún se cree que ser maestro es una profesión. Todavía hay quienes añoran un supuesto pasado de gloria en el que ser maestro sería un honor que la sociedad reconocía y premiaba. Es más, muchos creen que el maestro ha perdido su identidad o que se la disputan otras profesiones.

Se discute acerca del saber que le es propio al maestro, y sin embargo no hay acuerdo en torno al estatuto teórico de la Pedagogía: ¿ciencia? ¿arte? ¿disciplina?. Entre tanto hay un trabajo por hacer, una obligación que cumplir, un encargo por realizar, nunca un saber del cual dar razón.

El siguiente artículo, un tanto polémico, intenta aportar elementos para comprender las condiciones en que se constituyó lo que aquí se define como el oficio de enseñar. Oficio que ha sido encargado a un sujeto llamado maestro. ¿Quién es este personaje? ¿Quién es este sujeto que recientemente, en la sociedad moderna, ha desempeñado el rol de la enseñanza dentro de la institución escolar?

En este artículo se examinan las circunstancias históricas que rodearon la aparición y la institucionalización de este oficio durante el siglo XIX. La tesis fundamental es que el maestro no es aquel sujeto conciente, que movido por una supuesta voluntad natural, racional o divina, habría llegado a ocupar un puesto en la historia, reconocido luego por la sociedad y avalado por las instituciones modernas. Más que la historia de un sujeto lo que se quiere mostrar es cómo unos individuos fueron sujetados a un oficio. ¿Cómo se formaron ciertas instituciones, particularmente la escuela, en la que quedó atrapado este individuo? ¿Qué lugar ocupó allí el maestro?.

Ahora bien, la escuela no es entendida aquí como una institución formal con una dinámica independiente; la definimos más bien como acontecimiento. En este sentido, ella tiene sus márgenes delimitadas por un conjunto de prácticas que le señalan sus fines, su modo de funcionar y su estructura interna; dentro de este acontecimiento opera el maestro.

Veamos brevemente cuáles son las márgenes que delimitan la escuela en el siglo XIX 435.

\footnotetext{
*Este artículo forma parte de un trabajo de investigación sobre LA HISTORIA EN COLOMBIA: EL SIGLO XIX, realizado por el autor con la financiación de COLCIENCIAS y la Universidad Pedagógica y Tecnológica de Colombia.

${ }^{* *}$ Profesor del Departamento de Postgrado, Facultad de Educación. U.P.N.

${ }^{435}$ El desarrollo de estos puntos se encuentra en el trabajo sobre la historia de la Escuela al que se hizo referencia.
} 
1. En primer lugar el pensamiento de la época: los saberes, las nociones y los conceptos que desde diferentes lugares (no físicos) hicieron aparecer la instrucción como una necesidad. Múltiples circunstancias referidas a un conjunto de sucesos dispersos, hechos políticos, sociales y económicos de muy variada procedencia, fueron tejiendo una red compleja en la que el pensamiento se transformó (siglos XVII y XVIII). Nuevos enunciados se hicieron evidentes y se impusieron socialmente como verdades. De allí surgieron los saberes que hicieron de la instrucción una estrategia. Es decir, se convirtió en un propósito que convocó a toda la sociedad. De esa manera fueron emergiendo un conjunto de técnicas y mecanismos, llamados aquí Dispositivo, que hicieron realidad aquel propósito. Aquel conjunto de mecanismos, aquella máquina para instruir se materializa en la escuela, institución que viabiliza la estrategia; el dispositivo, entonces, es un mecanismo de Escolarización. El dispositivo de la Escolarización pone a operar una época en función del pensamiento que la delimita y le define sus características. De esta forma la escuela surge como un Acontecimiento de saber.

2. La otra margen que delimita la escuela es la del poder. Una serie de acciones minuciosas, cotidianas, a veces mezquinas y oscuras, realizadas por diferentes grupos sociales, van dándole a la escuela condiciones de posibilidad para instituirse. A ella no la define un decreto, ni una propuesta pedagógica, lo que la hace posible son las tensas relaciones que se establecen entre quienes van a ser sus principales protagonistas. Relaciones de fuerza, pugnas y luchas continuas entre los sectores implicados, van configurando una geografía del poder sobre la que se perfilan los contornos de la escuela.

Tenemos, pues, un modo de ser del pensamiento que se estrategiza, dando lugar a la Instrucción Pública; un Dispositivo que la viabiliza, escolarizando la población, y un conjunto de fuerzas que entran en pugna para impulsarla o para resistirla. De allí la escuela como acontecimiento de poder.

Concebida así la escuela, debe quedar claro que ella no es una institución creada por la voluntad política de un gobierno, quien, a partir de una determinada ideología, instituiría sus aparatos de dominación desde los cuales ejercer el poder. No es el sistema jurídico ni la legislación los que definen la escuela; tampoco es resultado de la evolución de la conciencia que al volver-se humanista piensa en la instrucción de las masas. Contrario a lo que comúnmente se piensa, la Pedagogía no es entendida aquí como la disciplina que en forma privilegiada habla de la escuela, como si ese saber contribuyera a instituirla; tampoco la escuela crea un saber propio que pudiéramos llamar Pedagogía.

La escuela es más bien un mecanismo que atrapa y articula enunciados dispersos ${ }^{436}$, los cuales, a su vez, la prefiguran, definiendo la forma de hablar sobre ella. De otra parte, la escuela es objeto de luchas y enfrentamientos, de pugnas y refriegas, siempre actuantes, siempre presentes, siempre creadoras $^{437}$. Del calor de la batalla es de donde surge la institución escolar.

Ahora bien, ¿Qué es la escuela?. Hasta ahora se ha explicado, someramente, cómo se instituye, pero: ¿Qué la compone?, ¿Qué la define?. Lo que pone a funcionar el mecanismo escolar es: el maestro, los ramos de instrucción (las materias que se enseñan) y el gobierno escolar (el sistema de normas que rigen en su interior). De manera que el maestro es definido aquí como parte de una máquina, de un dispositivo, de una

\footnotetext{
${ }^{436}$ En el primer capítulo del trabajo mencionado se hace referencia a los siguientes enunciados: La patria, los héroes, la agricultura, la enfermedad, la luz, la pobreza, la civilización y lo sagrado.

${ }_{437}$ En el tercer capítulo del mismo trabajo, se hace referencia a las siguientes fuerzas que entran en pugna: los vecinos, los curas y los funcionarios locales.
} 
técnica más amplia que es la escuela. En ese sentido no es posible hablar de su autonomía, de su saber o de su identidad. El problema, así, se vuelve más complejo.

Si queremos insistir en la propuesta de dotar al maestro de un estatuto profesional, es necesario conocer las fuerzas y los saberes instituidos que deben ser removidos, antes de seguir dando palos de ciego y actuando ingenuamente desde el voluntarismo que nos impone el deber ser.

Antes que una actitud fatalista o determinista, lo que se quiere suscitar con este artículo es una visión lo suficientemente aterrizada como para que nuestras acciones en procura de cambiar las condiciones del maestro y la escuela sean más eficaces.

La historia es utilizada aquí como martillo, con ella se intenta destruir los cimientos de nuestro presente y dejar el camino abonado para inventar uno nuevo.

Veamos entonces quién fue el maestro de escuela en el siglo XIX.

\section{Un apóstol}

Ciertas condiciones propias de la cultura le asignan al maestro un conjunto de responsabilidades que lo hacen Apóstol y Funcionario.

Se ha creado la necesidad de la instrucción de la juventud para construir la patria civilizada y próspera que el mundo reclama para las naciones, pero este requerimiento social hay que asignárselo a aquellas personas que reunan las condiciones necesarias.

Se trata pues de un encargo de la sociedad; todos los retos a los que se enfrenta la nación están hablando de los deberes que tiene aquel sujeto. No es solamente un mandato divino, también es un encargo de los hombres. Al principio no hay que definir reglamentariamente sus funciones, pues es el espíritu de la época el que reclama un hombre con cualidades de apóstol, que por demás dejan ver los valores vigentes de aquel siglo.

En cuanto encargo, debe entender su labor como un destino, pues está trazado el camino y no hay lugar a desviaciones. El mismo es parte de ese destino, su vida debe reglarse de acuerdo con las pautas de conducta que se le imponen. Además de ser un hombre capaz y de madura edad, debe ser de muy arreglada conducta y honrados procederes: constante, perseverante y de buena familia. Su vida, ejemplar y virtuosa, un hombre recto, buen súbdito y excelente padre de familia. Su abnegación y absoluta consagración a la Patria son imprescindibles. Se recomienda que sea casado y mayor de 18 años y no puede padecer enfermedad crónica o contagiosa.

Con todo, éste debe ser un oficio para ejercer por vocación. Quien no desempeñe el encargo con amor debe abandonar su puesto. Evidentemente se reconoce que es una ardua labor. De allí que se necesiten apóstoles, hombres que con singular y decidido empeño emprendan tan ingrata y difícil misión. $Y$ para ello debe reunir los siguientes requisitos:

...El Director de la Escuela, por la importancia de las funciones que ejerce, es uno de los primeros funcionarios del Distrito y tiene el deber de arreglar su conducta de manera que en su vida pública y privada sirva de tipo a todos los ciudadanos.., debe estar sostenido y animado por un profundo sentimiento de la importancia moral de sus funciones y fundar su principal recompensa en la 
satisfacción de servir a los demás hombres, y de contribuir al bien público... Se hará amar y respetar, no solo de sus discípulos, sino de toda la sociedad en que viva; será pudoroso y leal en relaciones, benévolo y afable en su trato, cumplido en sus maneras; pero deberá mostrar en todas ocasiones firmeza de carácter, para hacerse obedecer y respetar... las faltas graves contra la moral, así en su vida pública, como en su vida privada, serán castigadas en un Maestro de Escuela con la destitución del empleo... le está severamente prohibido el roce con personas reputadas como de mala conducta en el lugar, y la entrada a tabernas y casas de juego... Las autoridades dispensarán a los Directores de Escuela una consideración especial, una deferencia respetuosa, en atención al augusto ministerio que desempeña... no podrá, sin el permiso de la Inspección local, aumentar sus medios de subsistencia con el ejercicio de funciones accesorias, o de una profesión u oficio cualquiera y este permiso se rehusará siempre que el oficio o profesión comprometa la dignidad o moralidad del Institutor, o lo distraiga de sus funciones principales... ${ }^{438}$.

\section{"Señores maestros, la suerte de la Patria ha quedado depositada en vuestras manos..." 439 .}

Obviamente no puede ser menos que ingrata aquella misión y solamente apta para quienes estén dispuestos a sacrificar su vida en servicio a los demás: un apóstol. A él y al cura -mentores de la moral- se les ha confiado el sagrado deber de velar por el bien.

Pero la vocación no basta. No basta la buena voluntad y la intachable conducta, no basta la paciencia, la tolerancia y la fortaleza de carácter. Es necesaria, además del cúmulo de conocimientos, una destreza y una capacitación especial en el arte de enseñar.

Al principio es poco lo que se exige a este nivel: pericia en leer y escribir, tintura de aritmética y capacidad para imbuir a los jóvenes máximas sanas de moral cristiana y política. Pero poco a poco los requerimientos fueron mayores: entonces es necesario atender la cuestión a través del método. Este es un procedimiento fácil de aprender por el cual la enseñanza se hace efectiva y útil.

No es más, ciertamente, pero hay que estudiarlo. En las primeras tres décadas de la vida Republicana se ensaya la Escuela Mutua, aquella donde el maestro perito, a través de monitores, enseña el procedimiento a seguir en cada caso.

Algunas de estas escuelas se constituyen en las primeras Normales cuando expiden certificados que acreditan la adquisición de tres condiciones:

haberse instruido en el Método, tener buena conducta en lo político y moral, y desempeñarse en su destino en forma exacta y cabal.

Pero hacia 1844 ya se han presentado casos en que los preceptores fracasan en su intento por ser maestros. El diagnóstico de la situación en que se encuentran pocos hombres convenientemente instruidos en el arte de enseñar...

por tal motivo las rentas y contribuciones de los pueblos destinadas al sostenimiento de las escuelas parroquiales son con frecuencia perdidas, pues aquellos que las recibían, con pretexto de enseñar, son incapaces de hacerlo con utilidad ${ }^{440}$.

...por eso se señala como prioridad el establecimiento de Escuelas Normales. Allí deben los futuros maestros hacer el aprendizaje de los métodos de enseñanza para seguir la carrera de Directores de Escuela. Ante la falta de Institutores, hay que formarlos.

${ }^{438}$ El Boyacense No. 11, diciembre21 de 1886, pág. 83.

439 El Boyacense, No. 145, octubre 5 de 1888, pág. 1159.

440 Exposición del Secretario de Estado al Congreso Constitucional Bogotá, 1844. pág. 38. 
A partir de este momento la labor del maestro cobra cierto reconocimiento profesional. Entonces no es extraño encontrar avisos de prensa como el siguiente:

ZENON MARTINEZ
PEDAGOGO
Con Diploma de la Escuela Normal
ofrece sus servicios en su profesión
Guachetá, Diciembre 11 de 1877

Sin embargo, la estrategia de las Normales no es suficiente; el llamado a la vocación y a la buena voluntad es todavía común, igual que las quejas por la falta de personas capacitadas.

En la década del 70, para llenar las deficiencias de las Normales y cubrir los vacíos metodológicos, se les exige a los Maestros graduados de las cabeceras de cada Departamento que dicten a los Directores de las escuelas rurales lecciones prácticas sobre el método de enseñanza que tengan planteado en la escuela que dirigen.

El problema no es qué método (Lancasteriano o Pestalozziano) sino el método, cualquiera que sea. Lo importante es tener un mínimo de destrezas para cumplir con aquel destino. Pero cuando se trata de prepararse en la Normal para Maestro de Escuela Superior, la cosa se complica. Ya no es solamente el método. ¿Entonces qué se le exige a un Maestro que quiere portar un título?

Este es el diploma de un Maestro graduado en 1878:

DIPLOMA

DE MAESTRO DE ESCUELA SUPERIOR

EXPEDIDO AL SEÑOR ARISTIDES BELTRAN

No. 36

\section{ESTADOS UNIDOS DE COLOMBIA}

\section{ESCUELA NORMAL NACIONAL DE VARONES}

El Director de Instrucción Pública y los examinadores que suscribe, expiden el presente DIPLOMA DE CAPACIDAD para el desempeño de las funciones de Maestro de una Escuela Superior al señor:

\section{ARISTIDES BELTRAN}

Alumno de esta Escuela Normal, que ha sostenido por medio de las 
pruebas orales y escritas especificadas en el capítulo $X$ del reglamento para

Escuelas Normales, el examen público en las siguientes materias:

\section{CALIFICACIONES}

Lectura

Escritura

Aritmética

Gramática y Ortografía Castellanas

Geografía Universal y particular de Colombia

Geometría plana y en el espacio

Contabilidad

Física

Historia Patria

Dibujo

Canto

Pedagogía

Derechos y deberes del ciudadano

Calistenia

Francés

Legislación sobre Instrucción Pública

Arte de hablar

Algebra

Historia Natural

Química

\author{
Notable \\ Sobresaliente \\ Notable \\ Sobresaliente \\ Notable \\ Aprobado con plenitud \\ Sobresaliente \\ Notable \\ Id \\ Id \\ Id \\ Id \\ Aprobado con plenitud \\ Notable \\ Aprobado con plenitud \\ Id \\ Id \\ Id \\ Notable \\ Aprobado con plenitud ${ }^{441}$
}

¿Dónde está aquella especialidad para la cual se exigía tanta idoneidad? ¿Dónde y cuando se le enseña a enseñar?

Este problema lleva a una interesante polémica sobre lo que necesita saber un maestro para ser tenido en cuenta como tal. En principio hay acuerdo en que el Maestro lo que debe saber es enseñar, pero ¿Qué es enseñar? ¿Un Arte? si es así, ¿basta el talento? ¿o es necesario cultivarlo?. Quienes se inclinan por lo primero, consideran innecesarias las Normales; quienes creen que hay que cultivar el talento las defienden. El primer argumento es el siguiente:

"Cualquiera, sin instrucciones especiales, puede enseñar bien lo que ha aprendido bien... por lo tanto que se supriman las Escuelas Normales de Institutores, y que en lugar de perder el tiempo en estudios teóricos y prácticos de Pedagogía lo dediquen a ciencias profundas y positivas..."442.

El segundo argumento se plantea así:

...Las Escuelas Normales de Institutores son Escuelas de Oficio. El oficio del Maestro es enseñar. Por eso la enseñanza de las demás ciencias en las Escuelas Normales se considera solamente como un medio para llegar al fin que se tiene en mira de dichos establecimientos, a saber: educar Maestros. Visto está que la enseñanza es un arte que hay que estudiar. La ciencia que nos da a conocer este arte es la Pedagogía. Bien pudiera suceder que alguno aprendiera a enseñar asistiendo a buenas lecciones modelos e imitándolos en la práctica constante; pero en la época actual no satisface la mera rutina en la

${ }^{441}$ El Boyacense, No. 74, agosto 30 de 1878, pág. 296.

${ }^{442}$ El Boyacense. No. 33, agosto23 de 1884, pág. 131. 
enseñanza, pues el maestro debe darse teóricamente cuenta de su modo de proceder en cualquier punto y caso en la enseñanza; debe saber dar razón por qué en cada uno de los casos ha obrado de esta y no de aquella manera. El maestro tiene, por lo tanto, que aprender la Teoría de la ciencia de enseñar. La práctica sin la teoría es mera rutina. La enseñanza pedagógica tiene que ser teórica y práctica...."43.

La cuestión es delicada pues de hecho el pensum de las Normales no deja ver el peso real que la Pedagogía debe tener si se hace caso a este último planteamiento.

Pero lo que interesa destacar con relación a las Normales es la exigencia que se le hace a aquellos individuos que aspiran al magisterio. Ellos deben ir a prepararse en esas instituciones para solucionar el problema que se presenta con aquellos que no son capaces de enfrentarse al oficio con idoneidad. Esto es, la Normal es un requisito más de aquel encargo que la sociedad le ha entregado a los maestros; es una condición para poder dar cumplimiento a tan delicada misión. Lo que el Maestro hace es un servicio, pero para prestarlo, para sacrificarse por los demás, debe reunir todas las condiciones relatadas arriba, incluyendo la preparación en las Normales.

Ahora bien, ¿cómo vela la sociedad por el cumplimiento de esas condiciones?

\section{Un sujeto vigilado}

"FIJEMOS NUESTRA MIRADA ESCRUTADORA Y JUSTA EN LA CONDUCTA, VIDA PUBLICA O PRIVADA Y TENDENCIAS DE LOS MAESTROS; EXCLUYAMOS LOS MALOS COMO FRUTAS DAÑADAS DEL CESTO EN QUE ACOPIAMOS DULCES OBSEQUIOS PARA LOS NIÑOS, LLAMEMOS LOS BUENOS A EJERCER EL SANTO MAGISTERIO, SOSTENGAMOLOS EN SU LABOR CIVILIZADORA..."444.

El Maestro, antes que nada, es un sujeto controlado, vigilado y observado por quienes le encargan aquella misión apostólica. Dicha misión, como ya se dijo, proviene de las condiciones de saber en las que tiene su gestación la escuela. Pero la escuela necesita de un sujeto que encarne esa misión.

En una segunda instancia, pues, el maestro aparece como objeto del control de quienes portan aquel propósito moralizador y civilizador. Ellos lo crean a través de diferentes técnicas de vigilancia que operan a lo largo de todo el siglo XIX. Es decir, existe en cuanto objeto de observación, nace para ser visto; una máquina de visibilidades lo coloca en la historia para que lleve a cabo un encargo creado por los saberes de la época; un histórico destino lo gesta y le da por morada la escuela, un lugar estratégico para observarlo. La escuela es el cuadro a través del cual se hace visible el maestro.

\section{Pero ¿quiénes y cómo lo vigilan?}

\subsection{Los Curas}

Los curas son los más dignos representantes de la moral y deben guardar tan delicada prenda de los hombres. Ahora bien, en cuanto la moral es también una condición para construir la nueva Patria civilizada y próspera, se requiere una nueva estrategia: la

\footnotetext{
443 Ibid, pág. 132.

${ }^{444}$ El Boyacense. No. 168, febrero 19 de 1889, pág. 1342

Digitalizado por RED ACADEMICA
} 
instrucción. Para conseguir esto se hace necesario el dispositivo de escolarización, del cual el maestro es su primer componente.

Entonces, como nuevo guardador de la moral, el cura debe supervisar al maestro. Este se erige como parte de la autoridad que le asigna sus funciones y le condiciona sus valores; él observa su conducta y es consultado para decidir sobre sus nombramientos.

También es objeto de duras críticas por parte de los párrocos cuando la iglesia le declara la guerra a la escuela. Fenómeno frecuente, siempre que la estrategia de la instrucción no coincide con sus particulares intereses políticos ${ }^{445}$. En aquellos momentos los curas suelen enfrentarlo con los padres de familia desde el púlpito: estratagema por demás hábil pues, cuando logran su propósito, la escuela debe cerrarse. Sin maestro no hay escuela, pues aún le es imprescindible.

Lo que se percibe aquí es una paradoja. El maestro no es directamente el creador de aquel propósito moralizador, pero si es el blanco de las críticas cuando se enfrentan dos fuerzas en la disputa por la mejor estrategia. En todo caso su relación con los curas no es fácil. Incluso tiene que disputarle por momentos el lugar de hombre ilustrado que tradicionalmente tiene el párroco de los pueblos; en ocasiones es despojado de su puesto porque el cura ofrece servir a la escuela sin cobrar salario. El caso que se presenta en Chiquinquirá en 1823 ilustra esta tensa relación entre curas y maestros.

"Elevo al conocimiento de V.E. el expediente instruido por algunos vecinos y el Convento de Chiquinquirá, pretendiendo despojar al preceptor Francisco Guerra de su destino de maestro de escuela de enseñanza mutua colocando en su lugar a un hijo de aquellas parroquias, que según expresa su informe, el que actualmente la sirve no es apto para ello, si se halla aprobado en tal ejercicio... pero la solicitud de los vecinos y el Convento de Chiquinquirá es dirigida puramente a sofocar la paciencia del actual Maestro... Este Gobierno está bien informado de la buena conducta y procedimiento del Maestro Guerra y de que ha cumplido hasta hoy con su obligación a pesar de la resistencia de aquellos vecinos..." 446 .

El cura que le disputa la escuela al Maestro, ofrece lo siguiente:

"Que pasen los utensilios de la escuela Lancasteriana al Convento y que me den la gratificación que el vecindario quiera, que solamente instruiré en el método, en los derechos del hombre y moral cristiana; pues cada uno de los Religiosos aspiran a ser y criar hombres libres y emplearse en servicio de Colombia y sus pueblos. Fray Casimiro Arias Landine “447.

En medio de diferencias y enfrentamientos entre la Iglesia y el Estado, el siglo XIX no logra diferenciar la labor del maestro de la del cura, por eso su conducta es objeto de permanente mirada.

\subsection{El Examen}

Hasta hoy no se han conseguido todas las ventajas que eran de esperarse: efecto sin duda de la mala elección que con frecuencia se ha hecho de preceptores; porque estando la mayor parte de las escuelas mal dotadas, las autoridades a quienes está confiada la atribución de prever estos destinos se han visto muchas veces en la necesidad de conferirlos a personas incapaces de desempeñarlos con acierto. Por

\footnotetext{
${ }^{445}$ Nos referimos fundamentalmente a la década de 1870 , cuando la Iglesia se enfrenta ferozmente al gobierno liberal, entre otras cosas por la Reforma Instruccionista que instaura la educación laica, gratuita y obligatoria. Ver: Jane M. Loy, "Los ignorantistas y la escuela", en: Revista Colombiana de Educación, Bogotá, CIUP-UPN. No. 10, 1985.

${ }^{446}$ Archivo Histórico Nacional de Bogotá. Fondo Ministerio de Instrucción Pública. Leg. 106, Fols. 477488, mayo 14 de 1823.

447 Idem. 
otra parte, aquellas confiaban en el patriotismo e interés que presumían existía en las juntas curadoras que por ley estaban encargadas de examinar a los solicitantes y supervigilar su conducta después de posesionarlos... El nuevo plan de educación ha querido que los preceptores sean examinados en las capitales de provincia en donde regularmente hay hombres de conocimientos y que no estén inspirados por el espíritu del favoritismo, y tal medida ha empezado a producir buenos efectos, pues hemos visto que solo aquellos que tenían una íntima persuasión de salir con lucimiento en el acto, se han atrevido a presentar exámenes, mientras que la turbamulta de pedagogos que aspiraban antes ocupar estos destinos ha sido retraída por el temor de descubrir al público su nulidad.., en algunos pueblos se ha visto va hombres entregados a la crápula y a otros vicios detestables $y$ vergonzosos dirigiendo una juventud en quien tiene fincadas sus presuntas esperanzas la patria... ${ }^{448}$.

Queda pues planteado un problema: ¿Quién garantiza los conocimientos mínimos necesarios para ser maestro? De allí la necesidad de un sistema de control que poco a poco se institucionaliza: el examen. Ante el hecho de que muchos individuos aspiran ser nombrados como maestros buscando una vinculación laboral que les solucione su problema económico, se diseña este mecanismo del examen en las capitales de provincia para garantizar que tengan los conocimientos necesarios para ejercer el oficio.

Una de las modalidades del examen son los certámenes públicos que los estudiantes presentan dos veces al año. Del adelanto de los niños expresado allí se deducen las cualidades del maestro. Para eso se detallan al máximo los Planes de Estudio, para que el maestro, ciñéndose estrictamente a ellos, cumpla con los requerimientos establecidos por la estrategia de la instrucción. "Que el maestro se arregle puntualmente a lo que se previene en el Plan y los alcaldes celen su observancia" ${ }^{449}$.

Pero el problema es definir quiénes conceptúan acerca de las habilidades que en este campo deben poseer los preceptores. Tratándose de tan delicada función no es conveniente que las municipalidades decidan por sí mismas. Por eso se recurre a las capitales, donde se considera que habitan personas más capaces y mejor preparadas.

Ahora bien, con la creación de las Normales en 1842 se resuelve este problema. Esta es la institución que, a nombre de la sociedad, certifica sobre la idoneidad profesional de los futuros Directores de Escuelas. Pero, ya sean las municipalidades, los inspectores, los expertos o las Normales, lo que nos interesa mostrar es la forma como se constituye una instancia superior y externa al magisterio para que valide sus aptitudes y habilidades en el conocimiento:

...Sería conveniente que el maestro sin diploma, nombrado por las Municipalidades, no pudiera entrar en el ejercicio de sus funciones sin autorización previa del inspector departamental de Instrucción Pública. Siendo de advertir que dicha autorización debe otorgarse en vista del informe elevado por una comisión compuesta de tres individuos y que nombrará el mismo inspector, para el efecto de someter al maestro a un examen riguroso, sobre las materias que hayan de ser objeto de enseñanza... ${ }^{450}$.

...Para juzgar de los acontecimientos y método de enseñanza empleado por el Director, dispuse que, a mi presencia diera algunas lecciones; y el resultado en nada le favoreció... ${ }^{451}$.

...Para concesión de diploma de Maestro de Escuela Primaria o de Escuela Normal, será necesario un detenido examen teórico y práctico de todos los cursos que los reglamentos determinen como necesarios para la cuestión de tales diplomas. Terminado el examen el Consejo de examinadores lo calificará en votación secreta y determinará si el alumno examinado merece el diploma que solicita... ${ }^{452}$.

\footnotetext{
${ }^{448}$ El Republicano (Editorial). No. 5, marzo $1^{\circ}$ de 1811. pág. 1.

${ }^{449}$ Archivo Regional de Boyacá. Fondo Archivo Histórico de Tunja. Tomo II, mayo 9 de 1806, S.F.

${ }^{450}$ El Boyacense. No. 459, abril 27 de 1878, pág. 286.

${ }^{451}$ El Boyacense. No. 460, abril 23 de 1878, pág. 294

${ }^{452}$ El Boyacense. No. 11, diciembre21 de 1886, pág. 81. 
El examen es el instrumento apropiado para garantizar el control sobre el maestro. El examen como práctica de vigilancia, como modo de ser de la sociedad que se dispone a conseguir la Civilización y el Progreso.

El maestro es resultado del examen, el examen hace al maestro porque su papel también va a ser ese, él va a examinar y a vigilar en la escuela. Ese es su encargo. Una sociedad que vigila necesita un buen maestro.

\subsection{Los Padres de Familia}

Aunque no de una manera formal, el vecindario y los padres de familia también tienen un papel central en la supervisión del maestro.

En primer lugar, porque es un sector de vecinos llamados principales el que desde finales del siglo XVIII insiste en crear escuelas de primeras letras en sus municipios. Este sector de la municipalidad se convierte en un factor decisivo en el impulso a la Instrucción $\mathrm{y}$, por lo tanto, se siente con la autoridad suficiente para exigirle al maestro la conducta propia del proyecto político que impulsan. Son los llamados hombres de bien, notables, ilustrados o principales los que constantemente intervienen como fuerza social en la delimitación del perfil que adquiere la Escuela.

En segundo lugar, porque a los vecinos y pobladores en general se les exige desde un comienzo que contribuyan económicamente con las rentas necesarias para mantener la Escuela, rentas que se destinan casi en su totalidad al sostenimiento del maestro. Su salario depende durante todo el siglo de las rentas de propios (impuestos locales), o de las contribuciones extraordinarias que constantemente se les piden a los vecinos. De allí que se sientan con potestad sobre su labor.

En todo caso la opinión del vecindario es determinante para elegir, sustituir o mantener a los maestros en sus puestos. De una u otra manera su compromiso es con el público:

...ha desempeñado y desempeña llenamente los deberes de este su destino a satisfacción del público, observando una vida ejemplar y virtuosa, con la cual se ha granjeado el aprecio general.. ${ }^{453}$.

El Alcalde y algunos vecinos informaron que tenía hábitos vulgares y escandalosos... Incesantes son las quejas elevadas por todos los vecinos de este pueblo contra el Director de Escuela rural de este Distrito, por motivo de no ser competente para ejercer tan delicado empleo, puesto que carece de virtudes $y$ sobresale en vicios entregado a la embriaguez y jugando a la taba y al dado, que es la profesión que domina, dejando la escuela abandonada sin licencia de ninguna autoridad... ${ }^{454}$.

Son pues los vecinos un referente permanente del cual depende su vinculación laboral. De allí que sea considerado un hombre público: porque es el público el que lo está observando siempre, es al público a quien debe su trabajo, de quien debe ganar el aprecio y a quien debe su existencia.

\subsection{Las Juntas de Instrucción y la Inspección}

...proponiendo que no reciban a otro sino aquel cuyas costumbres hubieran sido regladas, capaz de imbuir a los jóvenes máximas sanas de una moral cristiana y política... que el cura, los jueces y tres vecinos principales relaten sobre la conducta del preceptor...

\footnotetext{
${ }^{453}$ Archivo Regional de Boyacá, mayo 8 de 1826, fol. 24r.

${ }^{454}$ El Boyacense, enero 18 de 1879, pág. 816.

${ }^{455}$ Archivo Regional de Boyacá. Fondo Archivo Histórico de Tunja. Vol. III, junio 23 de 1803, fols. 125r-129v. 
En 1868 se comienzan a reglamentar estas formas de control. Se le dan atribuciones detalladas a las llamadas Juntas de Instrucción Primaria para que examinen, remuevan o suspendan maestros. Sus miembros son pagados y forman parte de la estructura administrativa del Estado. También las corporaciones municipales tienen la facultad de suspenderlos cuando haya motivos graves.

Sin embargo, estas Juntas de Instrucción fracasan frecuentemente por falta de colaboración de los vecinos; por eso, en 1886 se dispuso que "toda escuela debe componerse de dos funcionarios: el que enseña a los niños y el que inspecciona y dirige al Maestro y hace efectivos el cumplimiento de los reglamentos y la asistencia de los alumnos..." 456 .

Realmente la labor de Inspector existe desde antes, pero no se le había entregado en forma tan clara esta responsabilidad de vigilante. La medida responde muy seguramente a una preocupación que hay por el mal desempeño en la labor asignada a los maestros. De tiempo atrás se vienen escuchando quejas por problemas en su comportamiento moral y en el conocimiento del método. Esto deja ver que formar aquel sujeto no es cosa fácil, hay que inventarlo, hay que moldearlo de acuerdo con los propósitos de la Escuela. Crear al Maestro supone un proceso largo que pasa por la invención de la Inspección. Del fracaso de las Juntas de Instrucción surge la necesidad de este dispositivo que ayuda a moldear el maestro ideal.

Pero los mecanismos dispuestos hasta aquí no bastan, las Normales tampoco, los títulos y certificados no son todo, los exámenes pueden ser excelentes pero no garantizan que el maestro vaya a cumplir con exactitud aquel mandato de la época. Además del cura, de los Inspectores, de los padres de familia, de las autoridades y de los examinadores, es necesaria otra forma de control.

\title{
2.5. El Libro de las Preparaciones
}

\begin{abstract}
...además de que es un poderoso auxiliar para el institutor, posee la ventaja de servir como termómetro para graduar los conocimientos y aptitudes del maestro; habilitándolo para descubrir nuevos medios para facilitar la enseñanza y conservar la disciplina escolar; adquiriendo también nuevas ideas, nuevos conocimientos y, en fin, nuevos sistemas que arrancarán de su base las ya inveteradas rutinas, propias de inteligencia apocada por pereza, el vicio o la embriaguez ${ }^{457}$.
\end{abstract}

Esa lucha permanente por meter en el molde aquellos sujetos que reciben la misión de enseñar, pasa por este último sistema que bien puede hoy llamarse parcelador. Hay que remover aquella indolencia intelectual que caracteriza a los maestros de la época (según el creador de esta ingeniosa técnica), y para hacerlos adoptar el tal libro de preparaciones "... había necesidad de proceder hasta con rigidez para obligarlos así a pensar, trabajar y meditar en los puntos y materias de enseñanza..." 458 .

Se instala el látigo a nombre del deber, de la inteligencia y de la pedagogía.

De lo anterior queda algo en claro: no es posible pensar que el maestro sea un hombre de prestigio, un líder de la comunidad o un intelectual. No hay tal constancia histórica, lo que tenemos para el siglo XIX es un Encargo y unos dispositivos para controlar a quienes lo asumen. No hay otra manera de ser maestro. Su destino es ser vigilado. Lo que encontramos para esos años es un esfuerzo múltiple por ajustar de la mejor manera el

\footnotetext{
${ }^{456}$ El Boyacense, No. 11, op.cit., págs. 81-82

457 El Boyacense, No. 15, agosto 10 de 1884, pág. 58.

458 Idem. 
trabajo de aquellos hombres voluntarios o no, a los requerimientos de la Escuela pública. Es decir, su labor es delineada desde afuera. El Método, la Normal, las Juntas de Vigilancia, el Libro de Preparaciones, los Exámenes, son todas técnicas con las cuales se intenta garantizar el cumplimiento de los propósitos de la Escuela. El cura, los vecinos, los inspectores, son quienes observaban con mirada escrutadora su comportamiento. Hay que velar para que toda su vida sea un testimonio, de manera que sobre su cuerpo quede esculpida la sociedad que promete el siglo XIX.

Pero, ¿qué piensa este personaje? Acaso tiene conciencia alguna de lo que sucede? ¿Acaso tiene oportunidad de pensar por un momento si quiere ser apóstol, intelectual o pedagogo? ¿Acaso de su corazón se escucha un llamado a cumplir con aquella misión? ¿Acaso se pregunta por su vocación? Quizá piense todo esto y además opte por una u otra alternativa en los diferentes momentos de su historia. No tanto porque alcance a ser consciente, sino porque es un componente de la Escuela y allí le es imperioso decidir. Siempre dentro del cuadro que lo hace visible, siempre desde las condiciones que le son señaladas por el destino que debe cumplir.

¿Se cierran aquí todas las posibilidades de pensar que hay factores de desequilibrio en toda esta estrategia? No. Aún faltan por estudiar las formas como actúa el poder en este juego instaurador de verdades. Lo cierto es que el maestro es creado e inventado, en principio, por ciertas formas de saber, de ver y de decir propias de la sociedad decimonónica. Entonces no es posible que él actúe como sujeto consciente, como protagonista de su propia historia. Tampoco es alienado, sometido y explotado; simplemente es inventado.

\section{Con todo, parece que tiene una preocupación...}

\section{Un mendigo de su salario} ...desde que estoy en este ministerio suplico rendidamente... se dignen mandar, se me satisfaga lo que
he devengado hasta la presente... pido y suplico, provean y manden como solicito... ${ }_{459}$.

En torno a este problema sí se escucha su voz; con recurrencia los documentos referidos al salario son escritos por los maestros. Allí dejan su huella y expresan su palabra. Pero generalmente es una voz de súplica mendicante. De alguna manera es la voz del servidor público, de aquel que se rebaja por los demás, de aquel sacrificado redentor que carga con las culpas de la humanidad.

El oficio es calificado siempre de laudable y patriótico, y la sociedad nunca se cansa de reconocer la abnegación y absoluta consagración que requiere aquella labor, pero el maestro es reprochado y censurado y su salario depende de la buena voluntad de los vecinos y de las empobrecidas rentas municipales.

Como ya se había dicho, los gastos de mantenimiento de la escuela son asignados a los vecinos, en especial los que corresponden al salario del maestro. En ocasiones los gobiernos nacionales y provinciales asumen los gastos referidos a los útiles, incluso los que tienen que ver con la manutención del local. Pero del salario de los maestros se encarga siempre la municipalidad. Tal obligación es suplida con fondos provenientes de múltiples entradas: rentas de propiedades (edificios o tierras), impuestos, alquiler de locales.., siempre inciertas y muy inestables. La otra fuente es la generosidad de algunos

\footnotetext{
${ }^{459}$ Archivo Regional de Boyacá. Fondo Archivo Histórico de Tunja. Vol. VI, septiembre 17 de 1807, S.F. Digitalizado por RED ACADEMICA
} 
vecinos, recurso que funciona ocasionalmente porque la mayoría de las veces se dice "que los vecinos no pueden adelantar más sueldo porque se hallan en suma pobreza" ${ }^{460}$.

Es decir que su salario es la única rueda suelta de toda esta máquina de propósitos, principios, controles e invenciones. Todo está previsto, menos los sueldos de los llamados a cumplir con el sublime encargo de instruir. Su única arma es la súplica, pero cuando sus condiciones no resisten, abandonan el puesto. ¿Es un problema de dignidad? o ¿de hambre?.

De hecho sus condiciones de vida son tan difíciles que en ocasiones se les compara con los indigentes. La pregunta de la época es:

¿Cómo vive un pobre maestro que al cabo de tres y más meses es que obtiene algo a cuenta de su sueldo?.., es imposible que sin la puntualidad en los pagos, el servicio que se exige sea completo... es falta de honradez, una crueldad, condenar a la miseria al ciudadano que consagra los mejores años de su vida al bien más grande que se puede hacer a un pueblo: instruirlo... ${ }^{461}$.

El arma del abandono es utilizada con alguna frecuencia, pero no antes de demandar por múltiples vías el pago de los sueldos atrasados. Esta demanda se hace con humildad y sumisión, aunque no faltan los pronunciamientos elevados de tono donde se ponen las cosas en claro "... es imposible que dedique el tiempo y consagración necesaria a la enseñanza porque primero que todo debo buscar los medios de subsistencia y estos no se encuentran en las escuelas..." 462 .

\section{Consideraciones finales}

Con este hecho se cierra el ciclo que se abrió para reflexionar sobre la primera visibilidad de la escuela. Se ha perfilado un oficio público y un prototipo de hombre para que lo desempeñe. El maestro existe en el marco de estas tres condiciones: un encargo sublime, unas técnicas de control y una vida de miseria. Tres condiciones históricas que le dan la vida a través de la escuela.

Queda sugerida una vía investigativa que poco se ha trabajado en Colombia. La Sociología de las profesiones desarrollada en otros países (especialmente sajones) sirve de ejemplo para señalar la importancia que tiene estudiar a fondo los problemas que se viven actualmente en los oficios del hombre moderno. Particular interés debería despertar a los maestros una línea investigativa como ésta, que dé cuenta de su situación laboral y del problema de su identidad.

Si tenemos como referencia estudios sobre otras profesiones, se lograría un análisis comparativo que nos permitiría dilucidar aquella pregunta formulada en la presentación: ¿ser maestro es una profesión?

Lo que quiero decir es que debemos llenarnos de razones para poder abordar con seriedad los problemas a los que se encuentra abocado el maestro colombiano. Sin el reconocimiento de las condiciones históricas en que ha laborado es imposible pensar su situación actual. Por eso se requiere de nuevos trabajos que complementen o corrijan los

${ }^{460}$ Archivo Histórico Nacional de Bogotá. Fondo Ministerio de Instrucción Pública. Legajo 106, julio $1^{\circ}$ de 1826, fol. $564 r$

${ }^{461}$ El Boyacense, No. 457, abril 6 de 1878, pág. 272.

${ }^{462}$ El Patriota, abril $1^{\circ}$ de 1838, No. 7. 
planteamientos hechos aquí. La inquietud no es simple. Se necesita un buen volumen de investigaciones relacionadas con el problema para avanzar con tesis más elaboradas y de mayor consistencia.

Lo que se dijo en este artículo seguirá siendo provisional mientras se desarrollan esos trabajos, pero desde ya, debe servir para provocar la discusión.

Bibliografía básica sobre el tema

ADORNO, Theodor. Tabúes relativos a la profesión de enseñar. En: Consignas. Buenos Aires, Amorrortu Editores, 1969, 181 pgs.

CALONJE, Patricia y QUINCENO, Humberto. El Maestro marginal: una historia por contarse. En: Educación y Cultura, No. 2. CEID-FECODE. Bogotá, septiembre de 1984, pág. 64.

CALONJE, Patricia. El círculo del tiempo y los maestros. En: tducación y Cultura, No. 7. CEID-FECODE. Bogotá, abril de 1986, pág. 12.

CARVAJAL S., Adalberto. Educadores frente a la ley. 3a. edición. Bogotá, Rodrigo Quito Editores, 1985.

CASTRO, Jorge Orlando. Educación pública y reforma educacionista en Colombia. Informe de Investigación. CIUP-UPN. Bogotá, 1990, 14 pgs.

CASTRO, Jorge Orlando y NOGUERA, Carlos. El estatuto del maestro en Colombia durante el siglo $X X$. Documento de trabajo preparado para el postgrado de evaluación escolar y desarrollo educativo regional. U.P.N. Bogotá, 1990, 27 pgs.

CATAÑO, Gonzalo. Educación y estructura social. Bogotá, Plaza y Janés. A.C.S., 1989.

CORAL, Laureano. Historia del Movimiento Sindical del Magisterio. Fondo Editorial Suramericana, Bogotá, 1980.

DE TEZANOS, Araceli. Maestros, artesanos intelectuales. Bogotá, U,P.N., CIID, 1985.

ECHEVERRY, Alberto. Historias de maestros. En: Educación y Cultura, No. 1. CEIDFECODE. Bogotá, julio de 1984, pág. 45.

ECHEVERRY, Alberto y ZULUAGA, Olga Lucía. El ocaso de la autonomía del maestro (1888-1903). En: Educación y Cultura, No. 10. CEID-FECODE. Bogotá, diciembre de 1986, pág. 29.

FERRO, Miryam Stella. Mi vida: Historia de la vida de una maestra rural colombiana. Bogotá, Editorial América Latina, 1978.

GOMEZ Buendía, Hernando y LOZADA Lora, Rodrigo. Organización y conflicto. La educación primaria oficial en Colombia. Ottawa. CIID, 1984.

HELG, Aline. La educación en Colombia: 1918-1957. Bogotá, CEREC, 1987, 334 pgs. 
MARTINEZ, Alberto; CASTRO, Jorge Orlando y NOGUERA, Carlos. Crónica del desarraigo. Bogotá, Cooperativa Editorial del Magisterio, 1989.

PARRA Sandoval, Rodrigo. Los maestros colombianos. Bogotá, Plaza y Janés, 1986, 314 pgs.

PARRA Sandoval, Rodrigo. El maestro y el desarrollo colombiano. En: Proyecciones Educativas, No. 1. Bogotá, MEN, 1982.

PARRA Sandoval, Rodrigo. Estudios sociales sobre el maestro colombiano. En: Revista Colombiana de Educación, No. 5. Bogotá, CIUP, 1980.

PERNET, José A. La imagen del maestro en la historia. No. 8, julio de 1986, pág. 12.

ZULUAGA, Olga Lucía. El maestro y el saber pedagógico en Colombia (7827-7848). Universidad de Antioquia. Centro de Investigaciones Educativas, Medellín, 1984. 